\title{
Job Preferences among Marginalized and Non-Marginalized Youth in Malaysia
}

\author{
Balan Rathakrishnan ${ }^{1 *}$, Samsudin A.Rahim ${ }^{2}$, Soon Singh $^{3}$, Bikar Singh ${ }^{4}$, \\ Juliana Rosmidah Jaafar ${ }^{5}$
}

\section{ABSTRACT}

This study aimed to explore the factor job preferences among youth in marginalized and nonmarginalized in Sabah. Preferences job four dimensions identified in this study, namely communality, job comforts, job goals and self-realization. The study will also explore the different job preferences by demographic background, namely gender and multi-ethnic. A total of 5954 youths was involved, ranging from marginalized $(\mathrm{N}=4107)$ and non-marginalized $(\mathrm{N}=$ 1847). The study found no significant differences in job preferences among marginalized and non-marginalized youth in Malaysia as a whole. However, job comforts show selected key factor in the youth as job preferences. For multi-ethnic difference that there were no significant differences for non-marginalized youth, but there are significant differences in the dimensions of self-realization for marginalized youth. The implications of this study are identified factor can contribute to the implementation of government policies to help young people get jobs.

Keywords: Job Preference, Marginalized

Career represent social role and the main energy source for the youth to meet the functionality of social life after completing his formal education system (Bandura, Barbaranelli, Caprara \& Pastorelli, 2001). Career is not only important to the role of youth in social, but also significantly associated with other individuals in social (Bluestein, Phillips, Jobin-Davis, Finkelberg \& Roarke, 1997). This is so because, career provides an extensive network of social relations while helping youth discover the opportunities of self-consciousness and economic resources.

\footnotetext{
${ }^{1}$ University Malaysia Sabah, Faculty of Psychology and Education, Sabah, Malaysia

${ }^{2}$ University Malaysia Sabah, Faculty of Psychology and Education, Sabah, Malaysia

${ }^{3}$ University Malaysia Sabah, Faculty of Psychology and Education, Sabah, Malaysia

${ }^{4}$ University Malaysia Sabah, Faculty of Psychology and Education, Sabah, Malaysia

${ }^{5}$ University Malaysia Sabah, Faculty of Psychology and Education, Sabah, Malaysia *Responding Author
}

Received: January 23, 2017; Revision Received: February 12, 2017; Accepted: February 15, 2017 (C) 2017 Rathakrishnan B, Rahim S, Singh S, Singh B, Jaafar J ; licensee IJIP. This is an Open Access Research distributed under the terms of the Creative Commons Attribution License (www.creativecommons.org/licenses/by/2.0), which permits unrestricted use, distribution, and reproduction in any Medium, provided the original work is properly cited. 


\section{Job Preferences among Marginalised and Non-Marginalised Youth in Malaysia}

Common issues are often encountered by youth either marginalized or non-marginalized is the career opportunities in their future. The issue is not only a challenge to the younger generation, but also the phenomena that occur pose a challenge to the world. Career opportunities in the future are one of the initiatives roles that could be done by youth as a member of a country. Initiative role of the youth is the same as another generation, which is contributes to economic growth and social development of the country. In particular, future career opportunities is very important to the growth of the youth, which is as an active young generation, providing resources, productive and thriving.

Marginalization occurs when individuals deterred from any opportunity to develop themselves, isolated from participation in society and do not have certain rights as is belonging to the dominant group. For the younger generation, the youth is marginalized from the development impacted on his ability to serve as active members of society in economic, cultural and political fields, especially future career opportunities. Marginalization occurs not because of the failure, a lack of talent or decline individual merits, but because of the poverty status of the individual. Unlike the non-marginalized youth open to development opportunities, to be actively involved in the role as a member of society, and not dealing with high difficulty in future career opportunities.

\section{Problem Statement}

Youth is the age group that tends to be affected and receive a big impact of marginalization of mainstream development. Mainstream development presents a challenge to youth in choosing their future career. Marginalization also affects the ability of youth, especially marginalized youth to meet their functionality as individuals in social, interpersonal and community. Marginalized youth also has limited control over their lives and the opportunity to source are limited, compared to the non-marginalized youth. In the context of a future career, the opportunities are limited and can cause marginalized youth develop a low sense of selfconfidence and self-esteem.

In modern society, a career is viewed not just as jobs that bring financial resources and meet the service, but the identity of his career high and self-assessment. For the youth, the career is a symbol of the role played in society, as a member of the contribution and active functional (Creed \& Scully, 2000). With a career, can indicate acceptance of society towards youth as working as an individual for the future. However, the challenges faced by youth in having a career are how they make future career choices. This is so because, career preferences is an important decision that not only have an impact on their own lives but also the next generation (Karlsen, 2001).

Karlsen (2001) explained there are two types of confrontation that could be explained factors influencing future career preferences among youths, which is the direct and indirect 


\section{Job Preferences among Marginalised and Non-Marginalised Youth in Malaysia}

confrontation. Direct confrontation referring to the socialization of labour, that youth is socialized to a culture of work or in other words is work-oriented career options. Meanwhile, confrontations indirectly refer to exposure to the working world are received in advance of the social environment (Bourdieu, 1990b). In other connotations, a youth was exposed to the world of work through observation of the world of work experience among parents or people around him during the growing period. Therefore, the observation of the experience factor influencing the choice of the future career preferences among youths (Berka, 2000). According to Karlsen (2001), indirect confrontation encourages orientation, selection and attitude to work.

However, Willis (1990) explain that the youths tend to depend on the formation of identity in choosing a career, for which the group puts the career as the symbol of work that allows them to move freely and creatively. Thus, youths are often in a situation of lack of control over work assignments solutions (Willis, 1990). Ziehe (1993) also emphasizes the youths still depends on expectations between dream and reality of life, which in modern society youths are not given a wide choice in choosing career preferences based on the freedom to move freely or creativity of its expectations and norms that have been established in the community about the career. Therefore, the youths to realize that career preferences based on a desire for a thing does exist in the social, but factor in choosing the career preferences that is likely to be frustrated due to a conflict with social expectations (Creed \& Scully, 2000; Karlsen, 2001). Thus, this study was conducted to explore the factor of choosing future career preferences of the youths based on four dimensions of career choice of communality, career goals, comfort career, and self-realization, which these factors were found to describe the career preferences based on the dreams and expectations of reality rather than social.

\section{Objectives}

Therefore, this study is based on the objectives, which is;

1. To study the differences in career preferences among marginalized and non-marginalised youth in Malaysia.

2. To study the differences of career preferences in terms of multi-ethnics in Malaysia.

\section{METHODOLOGY}

\section{Research Design}

This study is a quantitative method conducted surveys using questionnaires. This research will be used to explore different career preferences in the two groups of youth, which is marginalized and non-marginalized youths. In addition, the study will also explore the differences in career preferences of youth in Malaysia in terms of multi-ethnic. 


\section{Research Instrument and Participants}

The study conducted on 5,954 youth was divided into two groups of youth, which is marginalized and non-marginalized. The youths of 4107 the marginalized and non-marginal 1847 people.

The instrument used was aspirated from the instrument Work Preference by Karlsen (2001). The original instrument by Karlsen (2001) contains 13 items that career preferences are divided into 4 dimensions. Each dimension describes the career preferences, namely the altruistic dimension, career orientation, safety and comfort and self-realization. In this study, the researchers maintain 13 items of the instrument career preferences Karlsen (2001) and modified by adding 4 items to suit the objectives of the study in Malaysia. Thus, the whole item instrument in this study was 17 items. Dimensions derived from factor analysis were conducted by 4 dimensions, ie the dimensions of communality, career goals, career comforts and self-realization. Format scale feedback options are 5 options for each item, ranging from 'very important' to 'very important'. In addition, the study also contains background respondents' demographics including age, gender, and ethnicity of the youths.

\section{Data Analysis}

The researchers used data analysis t-test to see the differences between two different groups, which is, marginalized and non-marginalized youths. In addition, researchers are also using ANOVA test for both comparison groups multi-ethnic.

\section{RESULTS AND DISCUSSION}

\section{Results}

Table 1: Differences between Group of Career Preferences among Marginalized and NonMarginalized Youths.

\begin{tabular}{llll}
\hline Dimensions & Youths & Mean & Std. Deviation \\
\hline Communality & Marginalized & 4.149 & 0.767 \\
& Non-Marginalized & 4.273 & 0.657 \\
Career Goals & Marginalized & 3.779 & 0.681 \\
& Non-Marginalized & 3.835 & 0.658 \\
Career Comforts & Marginalized & 3.848 & 0.703 \\
& Non-Marginalized & 3.863 & 0.678 \\
Self-realization & & & 0.826 \\
& Marginalized & 3.751 & 0.830 \\
\hline
\end{tabular}

(c) The International Journal of Indian Psychology, ISSN 2348-5396 (e)| ISSN: 2349-3429 (p) | 180 


\begin{tabular}{llll}
\hline & $\mathbf{t}$ & df. & Sig (2-tailed) \\
\hline Communality & 6.384 & 4105.545 & 0.000 \\
Career Goals & 2.990 & 5946 & 0.003 \\
Career Comforts & 0.783 & 5952 & 0.434 \\
Self-realization & -0.416 & 5952 & 0.678 \\
\hline
\end{tabular}

According to Table 1, it was found that the factor in career preferences dimension of communality is the main factor for youth preferences both marginalized and non-marginalized, as a whole. Communality includes work at a place to stay, recognize people at work, like a lot of work; the work gives a sense of joy and helping people. The analysis also showed that there are significant differences between marginalized and non-marginalized in terms of communality and career goals. When viewed for the differences in dimension, non-marginalized youths showed high mean score $(4,273)$ compared to marginalized youths $(4149)$. Meanwhile, the second factor in career preferences is a career comfort, which is the freedom and satisfaction, independent work time, unlimited income, competition, make decisions and take risks. In terms of a difference in the youths, non-marginalized youths showed that the mean score is slightly higher $(3,863)$ than marginalized youths $(3,848)$ for the dimensions of career comforts. A third major factor is career goals, which include career choices based on wages, jobs, and power. It was found that non-marginalized youth showed higher mean score $(3,835)$ compared to marginalized youth (3779). Next, the last factor is self-realization, which includes art, religion, and virtue in choosing a career. It was found that marginalized youth shows a mean score slightly higher $(3,751)$ than non-marginalized youth (3741) in this dimension.

Table 2: Results of One way ANOVA for Career Preferences Factor among Youths by Multi-ethnic

\begin{tabular}{|c|c|c|c|c|c|}
\hline \multicolumn{2}{|l|}{ Dimensions } & \multirow{2}{*}{$\begin{array}{l}\text { df } \\
3\end{array}$} & \multirow{2}{*}{$\begin{array}{l}\text { MKD } \\
3.402\end{array}$} & \multirow{2}{*}{$\begin{array}{l}\text { JKD } \\
10.207\end{array}$} & \multirow{2}{*}{$\begin{array}{l}\mathbf{F} \quad \text { sig. } \\
6.281 * 0.000\end{array}$} \\
\hline Communality & BG & & & & \\
\hline & WG & 5950 & 0.542 & 3222.94 & \\
\hline \multirow[t]{2}{*}{ Career Goal } & BG & 3 & 1.373 & 4.119 & \multirow[t]{2}{*}{$3.018 * 0.02 \mathrm{c}$} \\
\hline & WG & 5944 & 0.455 & 2703.88 & \\
\hline \multirow[t]{2}{*}{ Career Comfort } & BG & 3 & 11.517 & 34.55 & \multirow[t]{2}{*}{$24.03 * 0.000$} \\
\hline & WG & 5950 & 0.479 & 2851.51 & \\
\hline \multirow[t]{2}{*}{ Self-realization } & BG & 3 & 94.902 & 248.70 & \multirow[t]{2}{*}{$148.8 * 0.000$} \\
\hline & WG & 5950 & 0.638 & 3793.23 & \\
\hline
\end{tabular}

$*_{k}<0.05$, 2-tailed, $B G=$ Between Group, WG=Within Group

(c) The International Journal of Indian Psychology, ISSN 2348-5396 (e)| ISSN: 2349-3429 (p) | 181 
Job Preferences among Marginalised and Non-Marginalised Youth in Malaysia

Table 3: Results of Post-Hoc Tukey on Factors Career Preferences among Youths by Multi-Ethnic

\begin{tabular}{|c|c|c|c|c|c|}
\hline Mean & Ethnic & 1 & 2 & 3 & 4 \\
\hline \multicolumn{6}{|l|}{ Communality } \\
\hline 4.213 & Melayu & - & $*$ & - & - \\
\hline 4.119 & Cina & $*$ & - & - & - \\
\hline 4.195 & India & - & - & - & - \\
\hline 4.216 & Others & - & $*$ & - & - \\
\hline \multicolumn{6}{|l|}{ Career Goals } \\
\hline 3.794 & Melayu & - & - & - & - \\
\hline 3.797 & Cina & - & - & - & - \\
\hline 3.882 & India & - & - & - & $*$ \\
\hline 3.767 & Others & - & - & - & - \\
\hline \multicolumn{6}{|l|}{ Career Comfort } \\
\hline 3.901 & Melayu & $*$ & - & - & - \\
\hline 3.725 & Cina & $*$ & - & $*$ & $*$ \\
\hline 3.877 & India & - & $*$ & - & - \\
\hline 3.898 & Others & - & $*$ & - & - \\
\hline \multicolumn{6}{|l|}{ Self-realization } \\
\hline 3.923 & Melayu & - & $*$ & $*$ & $*$ \\
\hline 3.401 & Cina & $*$ & - & $*$ & * \\
\hline 3.674 & India & $*$ & $*$ & - & $*$ \\
\hline 3.811 & Others & $*$ & $*$ & $*$ & - \\
\hline
\end{tabular}

Table 2 shows the results of the factor of career preferences among the multi-ethnic group in Sabah. Overall, the analysis found that the main factor in career preferences is communality $(4,187)$, followed career comforts $(3,852)$, career goals $(3796)$ and self-realization $(3,748)$. For the dimension of communality, found that youths from other ethnic groups (4216) showed somewhat higher than the mean score of Malays youths $(4,213)$ and Indian $(4,195)$. Chinese youths showed relatively low in communality dimensions $(4,195)$ than others. For the career comforts dimension, Malay youths $(3,901)$ prefer this factor in career preferences than other ethnic groups. Next, followed by the youth of ethnic others $(3898)$, Indian $(3,877)$ and Chinese (3725). For the third major factor is career goals, which is Indians (3882) showed that the mean score height of this dimension, followed by Chinese (3797) and Malay (3794). Meanwhile, a youth of ethnic others (3767) indicates a relatively low in mean score. Finally, factor the career preferences for self-realization appeared that youth of ethnic Malays $(3,923)$ preferring to factor this dimension, followed by a youth of ethnic others (3811) and Indian (3674). Chinese youths (3401) shows that the mean is relatively low.

(C) The International Journal of Indian Psychology, ISSN 2348-5396 (e)| ISSN: 2349-3429 (p) | 182 


\section{DISCUSSION}

Based on the results of the study clearly illustrates that there is a significant difference in terms of communality and career goals among marginalized and non-marginalized youths. When looking more in terms of communality clearly illustrates that the non-marginalized youths now want work nearby places a place to stay, recognize people at work, occupation is popular, job creating happy and helping people. The second factor the selection which showed a significant difference is career goals which are based on wages, jobs, and power. This is consistent with the national policy to establish mainstream youth want a permanent job and live near.

The encouraging job is a job that gives you the freedom and satisfaction in the workplace (Hyman, 1966). In fact, the work environment that stifles and mutually pressure not to give satisfaction to the non-marginalized youths. Therefore, a job that gives workers the freedom to provide satisfaction. Freedom refers to the decision-making and sharing insights (Jackson, 2000). This situation provides the non-marginalized youths more independent, creative and productive. These factors result in non-marginalized youths felt a thrill more at work near their homes and get to know people at work. It helps in understanding the culture of a workplace. This allows them to be more productive. In addition, the non-marginalized youths want jobs that make other people happy to be able to provide services to the public. With that, the non-marginalized youths identify themselves in terms of the ability of the chosen career. Dimension career comforts emphasize satisfaction for the non-marginalized youths to careers-centred satisfaction to yourself.

In terms of self-realization, non-marginalized youth emphasis on work in the form of art, religious and welfare in career preferences. This means that the non-marginalized youths nowadays choose jobs that emphasize a positive social relationship with the environment in the workplace. This dimension also emphasizes social relationships that enable non-marginalized youths interdependently and help individuals in the workplace environment. In addition, this dimension also emphasizes proficiency in the arts and creativity in choosing a career. Typically, non-marginalized youths who have talents in arts and creativity to choose a job that has such characteristics. This is because the job coincided with the interests and personality of the nonmarginalized youths itself. Moreover, the work coincided with personality characteristics will contribute to satisfaction and joy.

While in terms of career goal and communality not reflect any significant differences in the marginalized and non-marginalized youths. This is a situation that needs to be given greater attention in the future of youth do not give any attention to the work commonly performed now and work that emphasizes regular salary and regular income. The non-marginalized youth is more emphasizes work that gives freedom and has work related to art and religion. This is a new finding in this study as future generations will no longer focus on the work of the prevalent now and work related to fixed income. 


\section{Job Preferences among Marginalised and Non-Marginalised Youth in Malaysia}

In terms of career goal, the total wage is no longer a motivating factor for non-marginalized youths in choosing a particular field of work. Although the financial factor is a very important aspect of the life of the youth in both marginalized and non-marginalized but this factor is no longer a major factor in choosing a future career. This is because with financial aid alone cannot meet the needs of marginalized youth and daily living needs. In addition, getting permanent employment status does not necessarily give satisfaction to the non-marginalized youths because that status no longer reflects their true identity in the future. Now the selection is more work to satisfy ourselves whether they are from the marginalized or non-marginalized youths.

In terms of communality, the marginalized and non-marginalized youths no longer choose this factor as the main factor in choosing a career as an example close to home or to identify individuals in the workplace. The youths are more concerned about self-reliance without giving attention to the particulars of the location close to a place to stay, social relationships only with partners of their contacts. Youths now have an open mind and have an inherent desire to learn something new. Nature wants to learn this provides an opportunity for youth to learn new skills such as computer skills, soft skills and so on. All this is for the supply of youth in the future to be independent and have the competitive nature of that nature in their work.

Next, from the aspect of multi-ethnic differences are the Malays, Chinese, Indians and others, the analysis showed a significant difference in the difference factor of career preferences in multiethnic youth. In terms of communality, the youths of ethnic others showed mean score are relatively high compared to other ethnics. It explained that the youths of ethnic others are more likely to choose communality factor in career preferences. This is likely because other ethnic groups include the various ethnic groups in Sabah whose collective culture is still actively practiced. Factor in career goals, the youths of Indians prefer this factor in future career preferences. This is likely explained because the youths of Indians are more likely to choose a factor such as wages and job security and employment status is permanent rank. Next, the Malay youths tend to emphasize careers comfort and self-realization in their future career preferences. This can be seen when the youths of ethnic Malay tend to emphasize the work that is based on artistic, religious and welfare which enable it to build a positive social relationship with the environment. In addition, the preferences factor can also be influenced by the expectations of society that promote good social relations with each other.

\section{Implications}

Based on these findings, the researchers were able to identify the main factors influencing the career preferences among marginalized and non-marginalized youths. The factor identified to contribute to the implementation of government policies in helping the career earnings of the youths' future, thus reducing the rate of unemployment among youth. In fact, the factors that have been identified can help address the challenges faced by youth in career earnings going forward. 


\section{CONCLUSION}

In particular, this study aims to determine the differences factor the future career preferences among marginalized and non-marginalized youth. The study found that there are differences in career preferences factor among marginalized and non-marginalized youth in terms of factor communality and career goals. In addition, the study also looked at differences in career preferences among youth as a whole in the multi-ethnic. The study also explained that there is a significant difference between the four ethnic groups in all factor of future career preferences.

\section{Acknowledgments}

The author appreciates all those who participated in the study and helped to facilitate the research process.

Conflict of Interests: The author declared no conflict of interests.

\section{REFERENCES}

Bandura, A., Barbaranelli, C., Caprara, G.V., \& Pastorelli, C. (2001). Self-efficacy beliefs as shapers of children's aspirations and career trajectories. Child Development, 72, 187-206.

Blustein, D., Phillips, M., Jobin-Davis, M., Finkelberg, S., \& Roarke, A. (1997). A theorybuilding investigation of the school-to-work transition. The Counseling Psychologist, 25, 364-401.

Creed, W. E. D., \& M. Scully. (2000). Songs of Ourselves: Employees' Deployment of Social Identity in Work Place Encounters. Journal of Management Inquiry, 9(4), 391-412.

Hyman, H. (1966). The value systems of differents classes. In R. Bendix \& S. Martin Lipset (eds.) Class, Status and Power. Social Stratification in Comparative Perspective, pp. 488499. New York: The Free Press.

Jackson, F. L. (2000). Hegel's Psychology of Freedom. Retrieved from http://webcache.googleusercontent.com/search?q=cache:dGGQzJY4XloJ:www2.swgc.m un.ca/animus/Articles/Volume\%25205/jackson5.pdf+\&cd=9\&hl=en\&ct=clnk

Karlsen, U. D. (2001). Some things never change: Youth and occupational preferences. ACTA SOCIOLOGICA,44, 244-255.

Kerka, S. (2000). Parenting and career development. Eric Digest, No. 214. Retrieved from http://www.calpro-online.org/eric/docs/dig214.pdf

Willis, P. E. (1990). Common Culture. Symbolic Work at Play in the Everyday Cultures of the Young. Milton Keyned: Open University Press.

Ziehe, T. (1993). Kulturanalyser. Ungdom, utbilding og modernitet [Culture Analyses. Youth, Education and Modernity]. Stockholm: Brutus Ostlings Bokforlag Symposium.

How to cite this article: Rathakrishnan B, Rahim S, Singh S, Singh B, Jaafar J (2017), Job Preferences among Marginalised and Non-Marginalised Youth in Malaysia, International Journal of Indian Psychology, Volume 4, Issue 2, No. 89, ISSN:2348-5396 (e), ISSN:2349-3429 (p), DIP:18.01.097/20170402, ISBN:978-1-365-74162-3 